\title{
Combination of AG490, a Jak2 inhibitor, and methylsulfonylmethane synergistically suppresses bladder tumor growth via the Jak2/STAT3 pathway
}

\author{
YOUN HEE JOUNG $^{1 *}$, YOON MI NA ${ }^{1 *}$, YOUNG BUM YOO ${ }^{2}$, PRAMOD DARVIN $^{1}$, NIPIN SP $^{1}$, \\ DONG YOUNG KANG ${ }^{1}$, SANG YOON KIM ${ }^{1}$, HONG SUP KIM ${ }^{3}$, YOON HEE $\mathrm{CHOI}^{4}$, \\ HAK KYO LEE ${ }^{5}$, KYUNG DO PARK ${ }^{5}$, BYUNG WOOK $\mathrm{CHO}^{6}$, HEUI SOO KIM ${ }^{6}$, \\ JONG HWAN PARK $^{7}$ and YOUNG MOK YANG ${ }^{1}$
}

\author{
${ }^{1}$ Department of Pathology, School of Medicine, Institute of Biomedical Science and Technology; \\ ${ }^{2}$ Department of Surgery, School of Medicine, Konkuk University, Seoul 143-701; ${ }^{3}$ Department of Urology, \\ School of Medicine, Konkuk University Glocal Campus, Chungju 380-704, Republic of Korea; \\ ${ }^{4}$ Department of Biomedical Sciences, University College London, London, UK; ${ }^{5}$ Genomic Informatics Center, \\ Hankyong National University, Anseong 456-749; ${ }^{6}$ Department of Biological Sciences, College of Natural Sciences, \\ Pusan National University, Busan 609-735; ${ }^{7}$ College of Pharmacy, Dongguk University, Seoul 100-715, Republic of Korea
}

Received November 6, 2013; Accepted December 11, 2013

DOI: 10.3892/ijo.2014.2250

\begin{abstract}
Human urinary bladder cancer is the fifth most common cancer, with a worldwide estimate of about two million patients. Recurrence after complete transurethral prostatic resection is the most important problem in therapy. Combination therapy is a new approach in the treatment of cancers that do not respond to current therapies. These therapies have many advantages over conventional therapies, such as fewer side-effects and greater efficiency. Research efforts using natural compounds for the elimination or growth suppression of the cancer arise from studies on methylsulfonylmethane (MSM). MSM is a natural sulfur compound with no side-effects. AG490 is a tyrosine kinase inhibitor that has been extensively used for inhibiting Jak2 in vitro and in vivo. In our study, the combinatorial effect of these two agents on human bladder cancer cell lines and xenografts was analyzed. We observed that the combination of AG490 and MSM inhibited cancer cell viability and cell migration in vitro. This combination inhibited VEGF mRNA
\end{abstract}

Correspondence to: Dr Young Mok Yang, Department of Pathology, School of Medicine, Institute of Biomedical Science and Technology, Konkuk University, Seoul 143-701, Republic of Korea

E-mail: ymyang@kku.ac.kr

${ }^{*}$ Contributed equally

Key words: bladder cancer, Janus kinase 2/signal transducer and activator of transcription 3 pathway, methylsulfonylmethane, AG490, xenograft, metastasis expression in bladder cancer cell lines. In vivo experiments showed that oral administration of AG490 and MSM combination significantly inhibited the growth of tumor xenografts in mice. Our study clearly demonstrates that the predominant effect of this combination is the reduction of signaling molecules including STAT3, STAT5b, IGF-1R, VEGF and VEGF-R2 which are involved in the growth, progression and metastasis of human bladder cancer. The anti-metastatic ability of this drug combination is confirmed using metastatic animal models. Therefore, this combination could have the effect of genesistasis and powerful anticancer effects against bladder cancer.

\section{Introduction}

Human urinary bladder cancer is considered an increasingly significant public health issue in industrialized countries, with a worldwide estimate of about two million patients (1). Most of the patients have recurrence after a complete transurethral prostatic resection, which is the most serious problem in therapy (2-4). Men have 3-4 times higher risk of bladder cancer than women, and it increases with age (5). There are several post-operative chemotherapeutic agents or immuno-therapy for the prevention of recurrence. Although both medical and surgical approaches have been investigated, bladder cancer is still a recurrent disease (2-4). Therefore, new ways for the effective control of bladder cancer recurrence is required.

The research on natural compounds for tumor growth extinction or suppression showed a great potency and possibility in cancer management. Methylsulfonylmethane (MSM), is a natural organic sulfur from pine tree extract. MSM has not been developed as an anticancer compound; it is used as functional food $(6,7)$ with no reported side-effects. MSM has a powerful anti-angiogenic and anti-metastasis effect. It also 
has an inhibitory action for canceration in vivo (8). Many precedent studies defined reduction of angiogenesis and inducement of cell death in various cancer cells, but studies on human bladder cancer cells are relatively few (8-11).

Janus kinase (Jak) is tyrosin kinase which meditates the signal pathway by STAT adjacent to cytoplasma (12). AG490 is a tyrosine kinase inhibitor that has been extensively used for inhibiting Jak2 in vitro and in vivo (13). AG490 and its derivatives have been widely used for inhibiting Jak2, as a method of blocking STAT3 activation in vitro and in vivo $(14,15)$. AG490 has been shown to block Jak2 in patients with acute lymphoblastic leukemia and in genetically active variants of Jak2 at relatively low concentrations (16). In addition, AG490 variants such as WP1066 have been successfully used for treating cancers with active Jak2 and STAT3 $(17,18)$.

Signal transducer and activator of transcription (STAT) is a family of seven different transcription factors that play major roles in cytokine signaling (19). STATs are activated by ligand-bindings to specific cell surface receptors, and after tyrosine phosphorylation, dimerization and translocation to the nucleus, directly regulate target genes $(20,21)$. Especially, STAT3, which was first identified as an acute-phase response factor, was constitutively activated in many different tumor cell lines and in human cancers including breast, hematopoietic, head and neck, lung, prostate and ovarian cancers $(19,22)$. STAT3 is activated by growth factors including EGF, TGF- $\alpha$, IL-6, HGF and oncogenic kinases (12). In addition, this transcription factor has been shown to regulate the expression of genes involved in cell proliferation, anti-apoptosis and angiogenesis such as cyclin D1 and VEGF (23). Its phosphorylation is mediated through the activation of non-receptor protein tyrosine kinases called Jak $(12,24)$. STAT3 is phosphorylated primarily by Janus kinase (Jak1 and 2) at tyrosine 705 (25). Given the importance of constitutively active STAT3 in tumor growth and angiogenesis, targeting Jak2 has been considered a potentially good therapeutic strategy for anticancer therapy $(15,26)$.

Activated STAT3 proteins by cytokines and growth factor binds to the promoter of various gene products involved in anti-apoptosis (Bcl-2, Bcl-xL and survivin), proliferation (cyclin D1) and angiogenesis (VEGF) (27). VEGF is one of the most important growth factors involved in vasculogenesis and angiogenesis (28). VEGF-R2 is the main receptor for VEGFs, and its action is related to the activation of signaling molecules such as PLC $\gamma 1$, phosphoinositide-3 kinase (PI-3 kinase), Akt, Src and ERK (29). The VEGF gene and several other genes regulated by hypoxia and involved in oxygen homeostasis are under the control of the transcription factor HIF-1 (30). We have reported that STAT3 modulates VEGF through HIF-1 $\alpha$ (31). HIF-1 signaling pathway is known as a major mechanism in hypoxia signaling (32).

In our present study, we evaluated the efficacy of MSM together with AG490 not only for suppressing xenograft tumor growth, but also for lung metastasis. We confirmed the involvement of this drug combination in the suppression of STAT3 signaling both in vivo and in vitro. The molecular mechanism of Jak/STAT pathway inactivation was analyzed using the aggressive and non-aggressive bladder cancer cell culture system.

\section{Materials and methods}

Antibodies and reagents. Penicillin-streptomycin solution and fetal bovine serum (FBS) were purchased from HyClone (South Logan, UT). RPMI-1640 was purchased from Sigma Chemical (St. Louis, MO). Trypsin-EDTA $(0.05 \%)$ was purchased from Gibco-BRL (Grand Island, NY). STAT3, STAT5b, VEGF, VEGF-R2, IGF-1R, HIF-1 $\alpha$ antibodies and secondary antibody (goat anti-mouse and rabbit IgG-horseradish peroxidase) were obtained from Santa Cruz Biotechnology (Santa Cruz, CA). Phosphorylated STAT3 (Tyr705), phosphorylated JAK2 were purchased from Cell Signaling Technology (Beverly, MA). Jak2 was purchased from Millipore (Billerica, MA). Phosphorylated STAT5 was purchased from Upstate Biotechnology (Lake Placid, NY). $\beta$-actin was purchased from Sigma Chemical. The enhanced chemiluminescence (ECL) detection kit was purchased from Amersham Pharmacia Biotech (Piscataway, NJ). Restore ${ }^{\mathrm{TM}}$ Western Blot Stripping Buffer and NE-PER kit were purchased from Pierce (Rockford, IL). The electrophoretic mobility shift assay (EMSA) kit, oligonucleotide probes (STAT3), luciferase assay substrates, and reporter lysis buffer were purchased from Promega Corporation (Madison, WI). FuGene6 transfection reagent was from Roche (Basel, Switzerland). The RNeasy mini kit and Qiaprep spin miniprep kit were purchased from Qiagen (Hilden, Germany). RT-PCR Premix kit and VEGF, IGF-1R, 18s primer for RT-PCR were synthesized by Bioneer (Dajeon, Korea). Paraformaldehyde and mounting solution in immunohistochemistry (IHC) were purchased from Dae Jung Chemicals \& Metals Co. (Shiheung, Korea) and Life Science (Mukilteo, WA). Triton X-100 were obtained from Sigma Chemical. Methylsulfonylmethane (Fig. 1) that was purchased from Fluka/Sigma Co. (St. Louis, MO).

Cell culture and treatments. T24 and 253J-BV (gifts from Dr J.-H. Kim, Korea University, Korea) human bladder cancer cell lines were maintained in RPMI-1640 medium containing 10\% FBS, 2 mM glutamine and $100 \mathrm{U} / \mathrm{ml}$ penicillin. COS-7, monkey kidney cells were cultured in DMEM containing $10 \% \mathrm{FBS}, 2 \mathrm{mM}$ glutamine, $100 \mathrm{U} / \mathrm{ml}$ penicillin and incubated at $37^{\circ} \mathrm{C}$ in $5 \% \mathrm{CO}_{2}$. At the start of each experiment, the cells were resuspended in the medium at a density of $2.5 \times 10^{5}$ cells $/ \mathrm{ml}$. Cells were treated for the indicated duration with Jak2 inhibitor AG490 (Calbiochem, La Jolla, CA) (Fig. 1) at $25 \mu \mathrm{M}$ and MSM at $300 \mathrm{mM}$ and a combination of AG490 and MSM.

MTT assay. Cell viability was assayed by measuring blue formazan that was metabolized from 3-(4,5-dimethylthiazol-2-yl)-2,5-diphenyl tetrazolium bromide (MTT) by mitochondrial dehydrogenase, which is active only in live cells. The day before the drug application, cells were seeded in 96-well flat-bottomed microtiter plates (3,000-5,000 cells/well). Cells were incubated for $24 \mathrm{~h}$ with various concentrations of drug combination (AG490 and MSM). MTT (5 mg/ml) was added to each well and incubated for $4 \mathrm{~h}$ at $37^{\circ} \mathrm{C}$. The formazan product formed was dissolved by adding $200 \mu \mathrm{l}$ dimethylsulfoxide (DMSO) to each well, and the plates were read at $550 \mathrm{~nm}$. All measurements were performed in triplicate, and each experiment was repeated at least three times. 
A

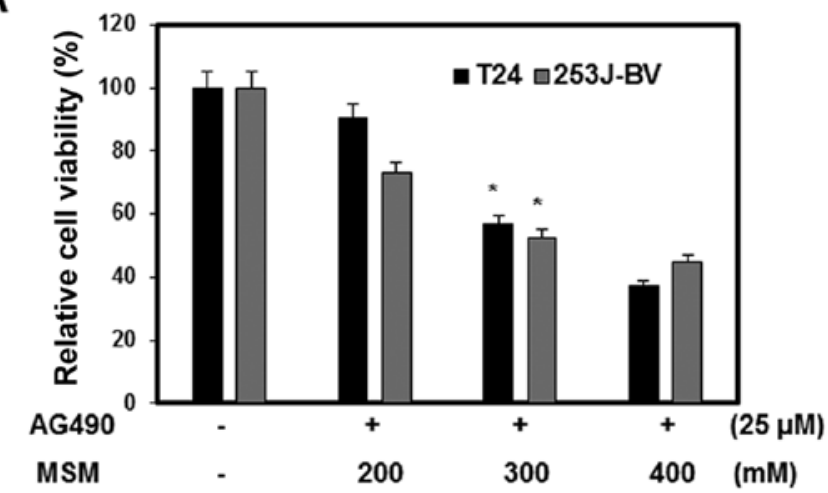

B

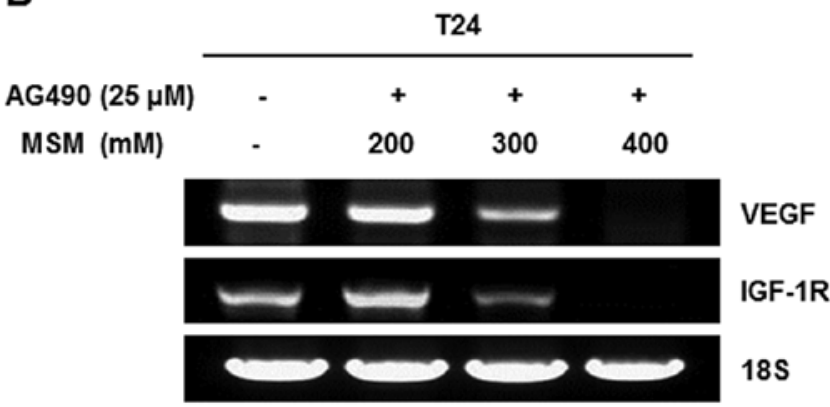

Figure 1. Combination of AG490 and MSM inhibited T24 and 253J-BV cell growth. (A) Evaluation of cell viability by MTT assay. Effect of drug combination on the viability of human bladder cancer cells T24 and 253J-BV for $24 \mathrm{~h}$. Cell growth was inhibited $\sim 52 \%$ at a concentration of $25 \mu \mathrm{M}$ AG490 and $300 \mathrm{mM}$ MSM. Asterisks (*) indicate an $\mathrm{IC}_{50}$ value (B) Effect of the combination of AG490 and MSM on the expression of VEGF and IGF-1R mRNA in T24 cells. 18S was used as a control.

Western blot analysis. Whole-cell lysates were prepared by scraping cells into $500 \mu 1$ RIPA (radioimmunoprecipitation assay) lysis buffer containing protease and phosphatase inhibitors and kept on ice for $10 \mathrm{~min}$. The lysate was centrifuged at $15,000 \mathrm{rpm}$ for $10 \mathrm{~min}$ at $4^{\circ} \mathrm{C}$ to clear the cellular debris. Protein concentrations were measured using the Bradford method. Equal amounts of proteins were resolved on SDS-PAGE and transferred onto nitrocellulose membrane. The blots were blocked for $1 \mathrm{~h}$ with $5 \%$ skim milk. It was then incubated over night at $4^{\circ} \mathrm{C}$ with the primary antibody followed by washing with TBS-T and incubated for $1 \mathrm{~h}$ with the secondary antibody. Detection was performed using the ECL detection kit and LAS-4000 imaging device (Fujifilm, Japan).

Immunoprecipitation. Whole-cell lysates were prepared by scraping cells into $500 \mu \mathrm{l}$ RIPA lysis buffer containing protease and phosphatase inhibitors and kept on ice for $10 \mathrm{~min}$. The lysate was centrifuged at $15,000 \mathrm{rpm}$ for $10 \mathrm{~min}$ at $4^{\circ} \mathrm{C}$ to clear the cellular debris. For immunoprecipitation, $500 \mu \mathrm{g}$ of whole-cell lysates was incubated with $3 \mu$ l anti-STAT3 antibodies for $3 \mathrm{~h}$ at $4^{\circ} \mathrm{C}$. Protein-G-agarose beads were added and the mixture was incubated overnight at $4^{\circ} \mathrm{C}$ on rocking platform. The mixture was washed 4 times in $1 \mathrm{X}$ IP buffer and once in 0.1X IP buffer. It was then resuspended in 1X Laemmli sample buffer and heat sample for $5 \mathrm{~min}$.
Immunoprecipitated proteins were subjected to western blot analyses as above.

Reverse transcription polymerase chain reaction (RT-PCR). Total cellular RNA was extracted using RNeasy mini kit (Qiagen) and quantified spectrophotometrically at $260 \mathrm{~nm}$. cDNA was synthesized from total RNA by reverse transcription at $42^{\circ} \mathrm{C}$ for $1 \mathrm{~h}$ and $80^{\circ} \mathrm{C}$ for 15 min using a first-strand cDNA synthesis kit (Bioneer). The synthesized cDNA was used as a template for PCR amplification. The primers were as follows: VEGF sense, 5'-AGGAGGGCAGAATCATCACG-3'; VEGF antisense, 5'-CAAGGCCCACAGGGATTTTCT-3'. The size of the amplified VEGF mRNA fragment was $312 \mathrm{bp}$. The PCR condition was $94^{\circ} \mathrm{C}$ for $5 \mathrm{~min}$ (denaturation), 30 cycles of $94^{\circ} \mathrm{C}$ for $1 \mathrm{~min}, 57^{\circ} \mathrm{C}$ for $1 \mathrm{~min}$, and $72^{\circ} \mathrm{C}$ for $1 \mathrm{~min}$ followed by $72^{\circ} \mathrm{C}$ for $8 \mathrm{~min}$. In addition, specific primers for 18s RNA were used as control. The primers were sense: 5'-CGGCTACCA CATCCAAGGAA-3' and antisense: 5'-CCGGCGTCCCTC TTAATC-3'. PCR products were resolved by $1 \%$ agarose gel electrophoresis and visualized by ethidium bromide staining.

Electrophoretic mobility shift assay. STAT3 DNA binding activity was detected using an electrophoretic mobility shift assay (EMSA), in which a labeled double-stranded DNA sequence was used as a DNA probe to bind an active STAT3 protein in nuclear extracts. Nuclear protein extracts were prepared with the Nuclear Extraction Kit (Panomics, AY2002). The EMSA experiment was performed by incubating a biotin-labeled transcription factor (TF-STAT3) probe with treated and untreated nuclear extracts. Nuclear protein extracts were prepared with the Nuclear Extraction Kit (Pierce). Reactions were resolved on a non-denaturing $8 \%$ PAGE gel (Bio-Rad, Gangnam, Korea). The protein gels were transferred to a nylon membrane and detected using streptavidin-HRP and a chemiluminescent substrate.

Cotransfection and luciferase reporter assay. Cells were co-transfected with various combinations of the following constructs; wild-STAT3 (gifts from Dr M. Shong, Chungnam National University, Korea); the VEGF reporter construct containing $2.7 \mathrm{~kb}$ of the VEGF promoter region. Transfected cells were washed with ice-cold PBS, lysed and lysates were used directly to measure luciferase activity. The luciferase activity of each sample was determined by measuring luminescence for $10 \mathrm{sec}$ on a Lumat LB 9507 luminometer (EG\&G Berthold, TN). The experiments were performed in triplicate, and similar results were obtained from at least three independent experiments.

253J-BV xenograft animal model. All procedures for the animal experiment were approved by the Committee on the Use and Care on Animals (Institutional Animal Care and Use Committee, Seoul, Korea) and performed in accordance with the institution guidelines. Male nude mice (Orient Bio, Seongnam-Si, Korea) were subcutaneous injected with highly metastatic human bladder cancer $253 \mathrm{~J}-\mathrm{BV}$ cells $\left(1 \times 10^{7}\right)$. The mice were maintained under specific pathogen-free conditions and used aged 5-8 weeks. The mice were divided into 3 groups and treated with 3\% MSM $(n=5), 3 \%$ combination $(n=5)$ for 1 month. No treatment was given to the control group of mice 
$(\mathrm{n}=5)$. The drug was administered as intragastric injections of $200 \mu \mathrm{l}$. Injections of $0.3 \mathrm{mg} / \mathrm{kg}$ body weight were given once a day, for 4 weeks. Tumor volumes were periodically measured with calipers. The tumor volume was calculated using the formula: tumor $\left(\mathrm{mm}^{3}\right)=$ maximal length $(\mathrm{mm}) \times$ perpendicular width $\left(\mathrm{mm}^{2}\right) / 2$.

Hematoxylin and eosin $(H \& E)$ staining. Histological analyses of xenografts were performed using H\&E staining. The animals were sacrificed and the xenografts were harvested surgically. These xenografts were fixed with $4 \%$ paraformaldehyde (Fisher Scientific, PA) and embedded in paraffin, and consecutive 5- $\mu \mathrm{m}$ thick sections were made, then deparaffinized and rehydrated with xylene, followed by a washing with gradient of $\mathrm{EtOH}(100,95,90,80$ and 70) and staining with H\&E (Sigma Chemical).

Immunohistochemistry (IHC). Formalin-fixed paraffinembedded xenografts were sliced into $5-\mu \mathrm{m}$ thick tissue sections. These tissue sections were deparaffinized, rehydrated with xylene, and washed with 100, 95, 90, 80 and $70 \mathrm{EtOH}$, permeabilized with Triton X-100 (0.1\%) and blocked with NGS (Normal Goat Serum in PBS 10\%). Incubated in a closed humid chamber with the STAT3, p-STAT3 and VEGF antibody followed with the secondary antibody, Alexa Fluor 488 (rabbit) and Alexa Fluor 594 (mouse) (Invitrogen, Carlsbad, CA). For nuclear staining, tissue sections were incubated with DAPI for $1 \mathrm{~min}$ and rinsed with PBS. The slides were then observed under a fluorescence microscope.

Wound healing assay. 253J-BV cells were plated on a 35-mm tissue culture dish at a concentration of $1 \times 10^{5}$ cells/plate in RPMI-1640 media containing 10\% FBS and antibiotics. Monolayers were scratched with a pipette tip and washed with PBS twice to remove debris. Cells were treated with AG490, 300 mM MSM, and a combination of AG490 and MSM. No treatment was given to the control cells. Wound edges were photographed after 24-h incubation.

Metastatic animal model. Primary tumors were induced by a subcutaneous injection of 253J-BV cells onto the flank of 5-week-old BALB/c nude mice (Orient Bio). The mice were randomly placed into three groups and treated with $300 \mathrm{mM}$ MSM and a combination in distilled water as intragastric injections of $200 \mu \mathrm{l}$. No treatment was given to the control mice. Treatment was given for 1 month and then the mice were euthanized and the lungs were removed. The number of metastatic tumors on the lung surface was counted. The lungs were fixed with $4 \%$ paraformaldehyde. The sections were stained with $\mathrm{H} \& \mathrm{E}$, metastatic nodules were counted, and the mean number of nodules was recorded as the number of metastases.

Analysis of apoptosis. Fluorescein-conjugated Annexin V (Annexin V-FITC) was used to quantitatively determine the percentage of cells undergoing apoptosis. Treated cells were washed twice with cold PBS and then resuspended in binding buffer at a concentration of $1 \times 10^{6}$ cells $/ \mathrm{ml}$. Annexin V-FITC $(5 \mu \mathrm{l})$ and propidium iodide $(5 \mu \mathrm{l})$ were added to the suspended cells. After incubation for $15 \mathrm{~min}$ at room temperature in the dark, the percentage of apoptotic cells was analyzed by flow cytometry (Becton-Dickinson FACScan, San Jose, CA). For positive controls, $10 \mu \mathrm{M}$ camptothecin and $23 \mu \mathrm{M}$ actinomycin D were used.

Data analysis and statistics. The results of the experiments are expressed as mean \pm SEM. Statistical analysis was performed by ANOVA-tests using the SAS program.

\section{Results}

Combination of AG490 and MSM inhibits T24 and 253J-BV cell growth. The effect of the combination of AG490 and MSM on cell viability was examined by the MTT assay. Human bladder cancer cell lines T24 and 253J-BV were exposed to different concentrations of MSM and a fixed concentration of AG490 $(25 \mu \mathrm{M})$. The number of combination treated cells in the logarithmic phase of growth was compared with that of the control cells. Combination treatment inhibited the growth of T24 and 253J-BV cells in a dose-dependent manner. The $\mathrm{IC}_{50}$ dosage of the combination was $300 \mathrm{mM}$ MSM with $25 \mu \mathrm{M}$ AG490 for $24 \mathrm{~h}$ of treatment. Higher concentration of MSM (400 mM) inhibited cell growth by about $60 \%$ (Fig. 1A). To determine the effect of the combination of AG490 and MSM on the expression of VEGF and IGF-1R mRNA in T24 cells, total RNA was extracted from cells treated with various concentrations of MSM. This mRNA was examined using RT-PCR analysis. MSM decreased the expression of VEGF and IGF-1R mRNA in a dose-dependent manner in $24 \mathrm{~h}$. At a concentration of 300 and $400 \mathrm{mM}$ MSM, the expression of VEGF and IGF-1R mRNA was inhibited in T-24 cells (Fig. 1B).

Combination of AG490 with MSM suppresses Jak2 activation in a time-dependent manner. Our next goal was to analyze the time-dependency of the combination of AG490 and MSM on the protein expression of T24 cells and 253J-BV cells. The cells were incubated with $25 \mu \mathrm{M}$ AG490, 300 mM MSM and combination for different time periods. Total cellular proteins were extracted and lysates were immunoblotted with specific antibodies. As shown in Fig. 2A, there was a rapid fall in the activation of Jak2 in the combination treated cells. This inhibition was similar in both T24 and 235J-BV cells (Fig. 2A and C). The inhibition of Jak2 activation remained for $30 \mathrm{~min}$ and then gradually reversed, whereas in the cells treated with AG490 or MSM alone, a mild, or no inhibition on the Jak2 activation was found (Fig. 2A, panel 1). The time window on Jak2 inhibition shows better inhibition between 5-20 min in both T24 and 253J-BV cell lines (Fig. 2B and D). Phospho-Jak2 was detected by immunoblot analysis with anti-phosphotyrosine (4G10) antibody after Jak2 immunoprecipitation. We confirmed that combination of AG490 with MSM suppressed Jak2 phosphorylation within $20 \mathrm{~min}$ (Fig. 2E).

Combination of AG490 with MSM suppresses STAT3 activation time-dependently. Our next goal was to check the impact of Jak 2 inhibition on the activation of STAT3. We observed a gross inhibition of STAT3 activation within $3 \mathrm{~h}$ on exposure to the drug combination whereas mild, or no inhibition on treatment with AG490 or MSM alone (Fig. 3A). The inhibi- 
A

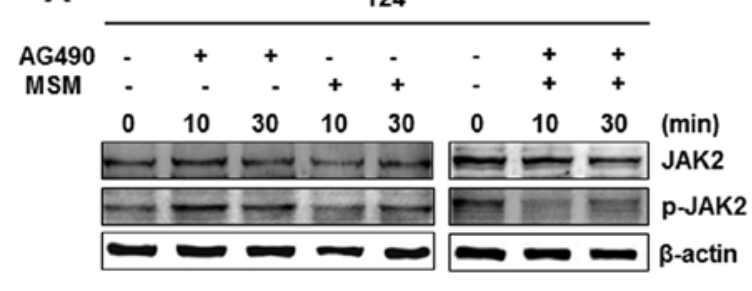

C

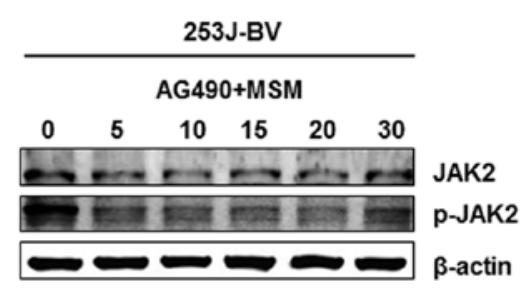

E

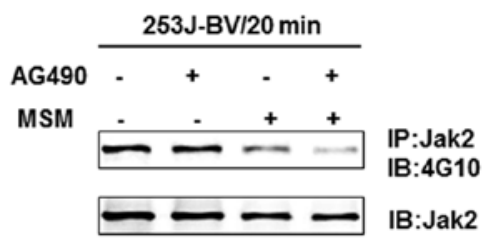

B

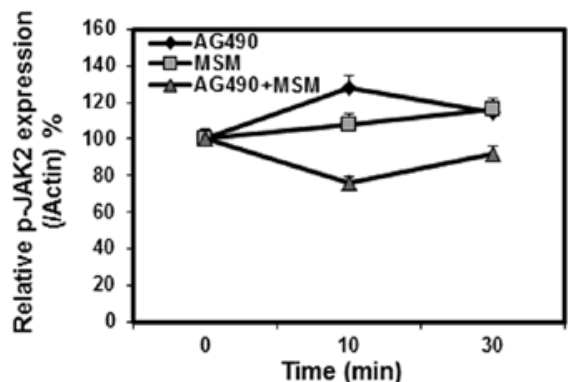

D

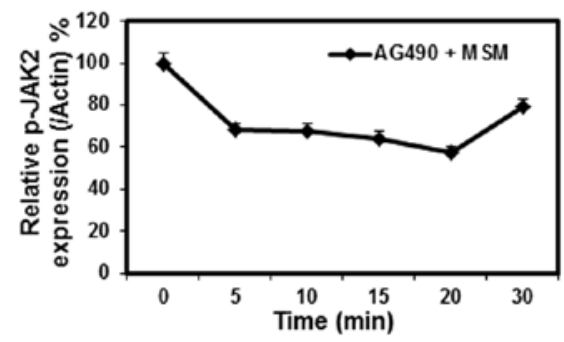

F

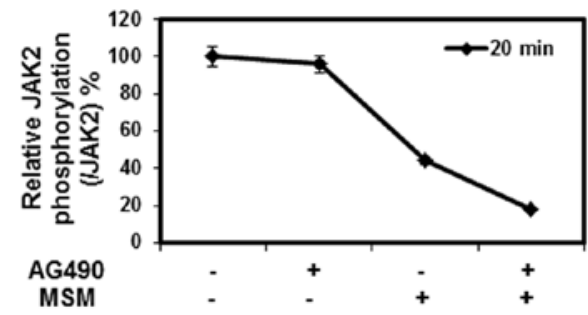

Figure 2. Combination of AG490 with MSM suppresses Jak2 activation time-dependently. T24 and 253J-BV cells were treated with a combination of $300 \mathrm{mM}$ MSM and $25 \mu \mathrm{M}$ AG490 as indicated. (A) The comparative effect of individual agents and the drug combination on the phosphorylation of Jak2 in T24 cells. (B) Relative expression of p-Jak2 at different time periods. (C) The effect of the drug combination on the phosphorylation of Jak2 in 253J-BV cells. (D) Relative expression of p-Jak2 in different time periods. (E) Jak2 precipitation and the phosphorylation status of Jak2 were analyzed by western blot analysis with anti-Jak2 and anti-phosphotyrosine (4G10) antibodies. (F) The relative levels of Jak2 phosphorylation were determined using densitometric analysis and normalized to the amount of Jak2.

tion of STAT3 activation was similar in both bladder cancer cell lines (Fig. 3A and C). To check STAT3 inhibition either by Jak 2 or by any other tyrosine kinase, we analyzed the expression and activation of AKT. As a result, there was no alteration in the activation of AKT by combination treatment (Fig. 3C). Relative protein expression studies give a better view of STAT3 inhibition. Here it is found that inhibition of STAT3 activation in both T24 and 253J-BV cell lines is between 3-6 h by the drug combination (Fig. 3B and D). Cell lystates were immunoprecipitated with anti-STAT3 antibody, followed by immunoblot analysis with anti-phosphotyrosine (4G10) antibody. These results demonstrate that the combination of AG490 with MSM suppressed STAT3 phosphorylation within 5 h (Fig. 3E).

AG490 and MSM combination exposure leads to the downregulation of STAT3 target gene product VEGF. Our previous research showed that the best inhibition of STAT3 phosphorylation was between 3 to $6 \mathrm{~h}$. We analyzed the expression of target genes of STAT3 after its inhibition with combination of $25 \mu \mathrm{M}$ AG490 and $300 \mathrm{mM}$ MSM for different periods of time. The RT-PCR analysis showed a decrease in the transcription of VEGF mRNA (Fig. 4A). The results showed the transcriptional level regulation of VEGF expression upto $6 \mathrm{~h}$ and after that, it started to regain its expression. AG490 alone did not show any role in transcriptional regulation of VEGF whereas a $40 \%$ inhibition was found on treatment with $300 \mathrm{mM}$ MSM (Fig. 4C). The combination treatment exhibited a synergistic effect and induced $80 \%$ inhibition on VEGF compared with control (Fig. 4D). Relative expression of VEGF showed a similar inhibition level by combination treatment in both T24 and 253J-BV cell lines (Fig. 4B and D).

AG490 and MSM combination exposure leads to downregulation of STAT3 promoter activities. Activated STATs form dimers, translocate into the nucleus, bind to specific response element in the promoters of target genes and activate those genes (33). Using EMSA, we analyzed the binding activity of p-STAT3 on VEGF gene promoter. As expected, scarce DNA-STAT3 complex was observed in cells treated with combination of $25 \mu \mathrm{M}$ AG490 with $300 \mathrm{mM}$ MSM (Fig. 5A). The western blot analysis of nuclear extracts showed a decreased level of p-STAT3 in cells treated with the drug combination. Near normal or slight inhibition of p-STAT3 level was observed in AG490 or MSM treated cells, respectively (Fig. 5B). Apart from this, the expression level of VEGF, VEGF-R2 and HIF-1 $\alpha$ were suppressed by the drug combination. We performed luciferase reporter assays to confirm the inhibition of transcriptional activities by combination treatment. As shown in Fig. $5 \mathrm{C}$ the relative 
A

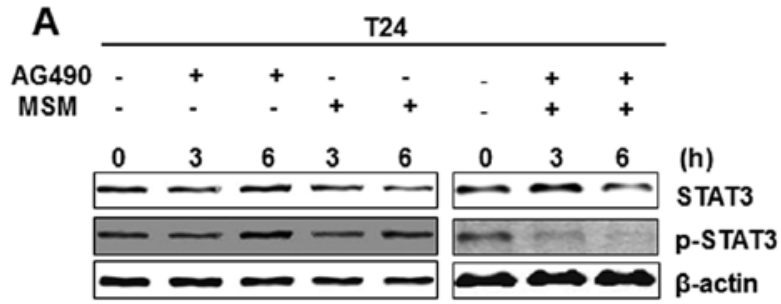

C
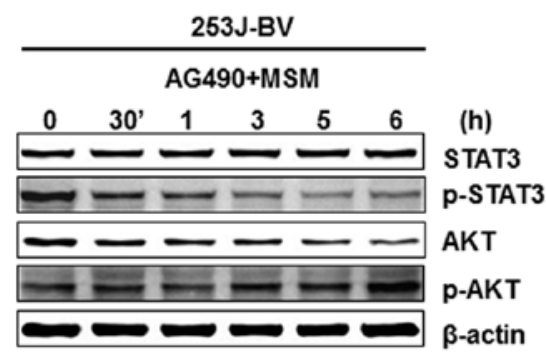

E

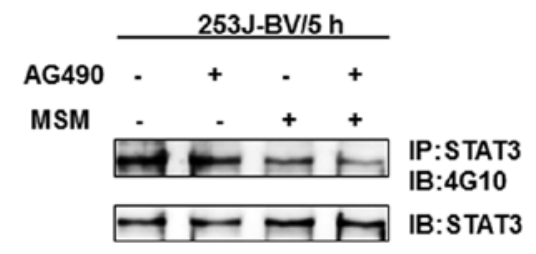

B

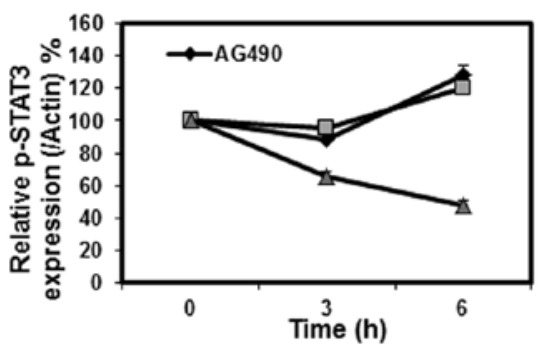

D

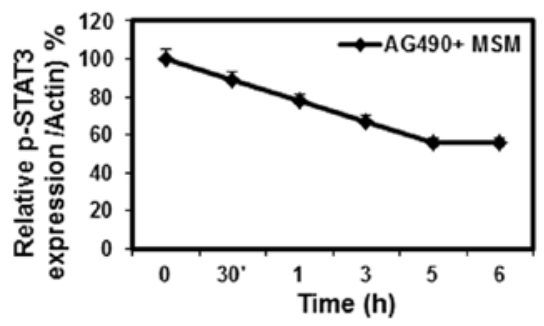

$\mathbf{F}$

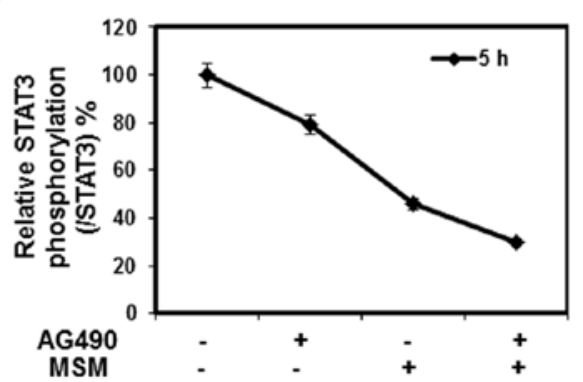

Figure 3. Combination of AG490 with MSM suppressed STAT3 activation time-dependently. T24 and 253J-BV cells were treated with $300 \mathrm{mM}$ MSM and $25 \mu \mathrm{M}$ AG490 as indicated. (A) The comparative effect of individual agents and the drug combination on the phosphorylation of STAT3 in T24 cells. (B) Relative expression of p-STAT3 in different time period. (C) The effect of the drug combination on the phosphorylation of STAT3 and Akt in 253J-BV cells. (D) Relative expression of p-STAT3 in different time period. (E) STAT3 precipitation and the phosphorylation status of STAT3 were analyzed by western blot analysis with anti-STAT3 and anti-phosphotyrosine (4G10) antibodies. (F) The relative levels of STAT3 phosphorylation were determined using densitometric analysis and normalized to the amount of Jak2.

luciferase activity of STAT3/VEGF promoters were inhibited about $90 \%$ by combination treatment. Treatment with AG490 only showed comparatively less effect whereas MSM gave a significant inhibition in luciferase activity, showing its role in the combination treatment.

AG490 and MSM combination downregulates the expression of different oncoproteins. The role of AG490 and MSM combination on the expression of different oncoproteins were compared with that of AG490 and MSM alone. The T24 and 253J-BV cells were treated with AG490, MSM and drug combination for $6 \mathrm{~h}$ and the level of protein expression was assayed using western blot analysis. We found that AG490 did not affect the expression of oncogenic proteins and the expression level was close to the control level. MSM and the drug combination treated cells showed decreased expression of oncoproteins. MSM showed no regulation on the expression of STAT3 in bladder cancer cell lines, but in combination with AG490, it regulated the expression as well as suppressed the phosphorylation in both cell lines (Fig. 6). Other oncogenic proteins such as VEGF-R2, p-STAT5, STAT5b, IGF-1R, HIF-1 $\alpha$ and AKT were also downregulated by AG490 and MSM combination (Fig. 6A). In 253J-BV cells, the expression of VEGF-R2, STAT5b, IGF-1R and HIF-1 $\alpha$ were decreased, but the phosphorylated level of STAT5b and IGF-1R were observed as not altered in 253J-BV cells (Fig. 6B).

Combination of MSM and AG490 suppresses tumor growth and induces cell death in human bladder cancer xenografted mice. To confirm the in vivo role of the drug combination and to analyze the synergistic effect of the drug combination we included MSM as a reference trial drug. Tumor xenografts were induced by subcutaneous administration of 253J-BV $\left(1 \times 10^{7}\right)$ human bladder cancer cells. Drug treatment started 2 weeks after the inoculation of cells, with dose of $0.3 \mathrm{mg} /$ $\mathrm{kg} \mathrm{MSM}$ or $25 \mu \mathrm{l} / \mathrm{kg}$ AG490 with $0.3 \mathrm{mg} / \mathrm{kg}$ MSM given once a day. Tumor volumes were measured every day with calipers and harvested during the 4 th week. As shown in Fig. 7B, treatment with drug combination led to a significant inhibition of tumor growth and decreased the final tumor size by $32 \%$, whereas, treatment with MSM did not result in a significant reduction of the final tumor growth $(110 \%)$. Control group showed $150 \%$ increase in tumor growth (Fig. 7A). In the xenograft model, apoptosis was associated with tumor necrosis. Histologic examination of the xenografts using H\&E staining showed increased tumor cell death in animals treated with combination of MSM and AG490 when compared to the MSM treated group and control group (Fig. 7C). 
A
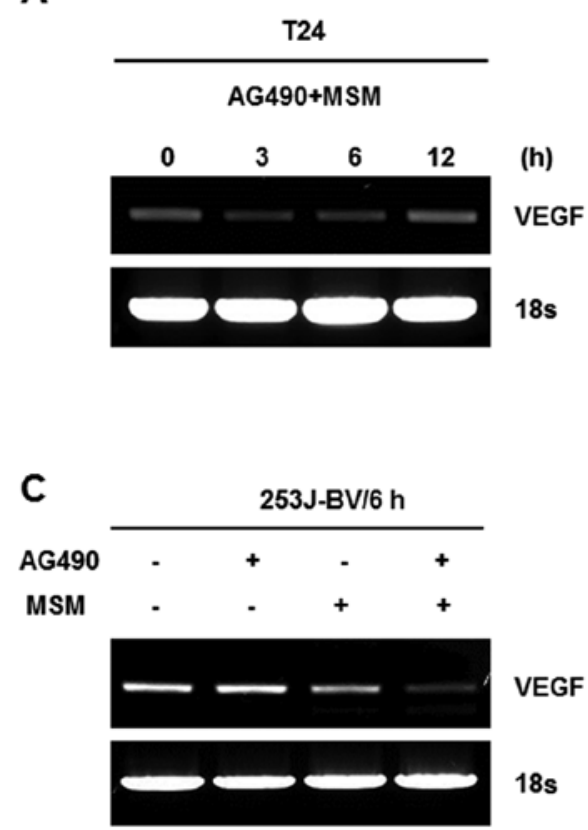

B

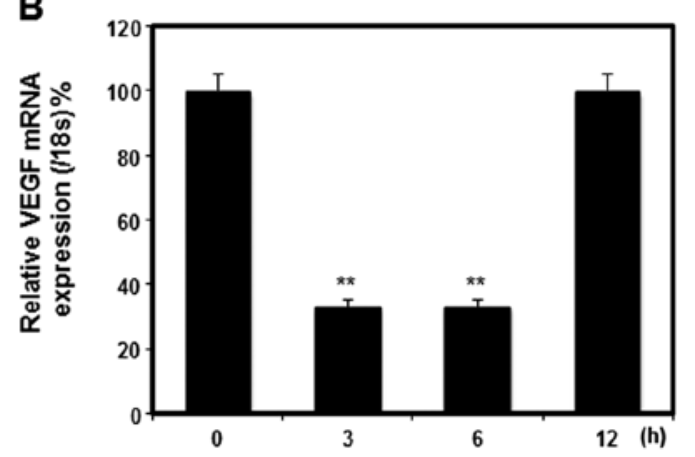

D

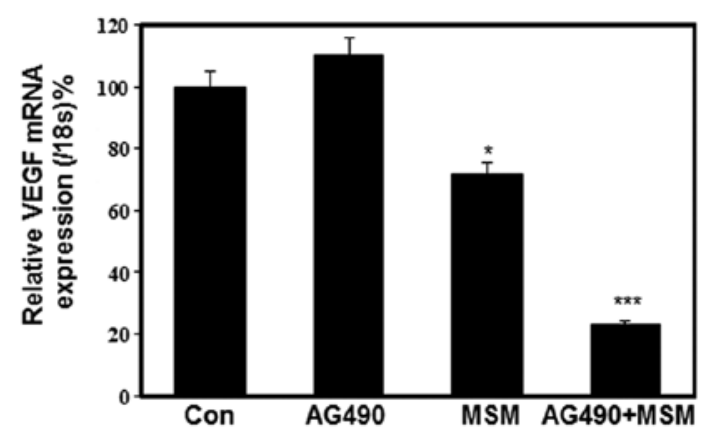

Figure 4. AG490 and MSM combination exposure leads to the downregulation of STAT3 target gene product VEGF. RT-PCR analysis showed a downregulation of VEGF expression. (A) The time dependent effect of drug combination on the expression of VEGF in T24 cells. (B) Relative VEGF mRNA expression in T24 cells with respect to time. (C) The comparative effect of individual agents and the drug combination on the expression of VEGF in 253J-BV cells. (D) Relative expression of VEGF mRNA in 253J-BV cells on treatment with individual agents and combination. Asterisks indicate a statistically significant decreased by ANOVA-test $\left({ }^{*} \mathrm{p}<0.05,{ }^{* *} \mathrm{p}<0.01,{ }^{* * *} \mathrm{p}<0.001\right)$.

A

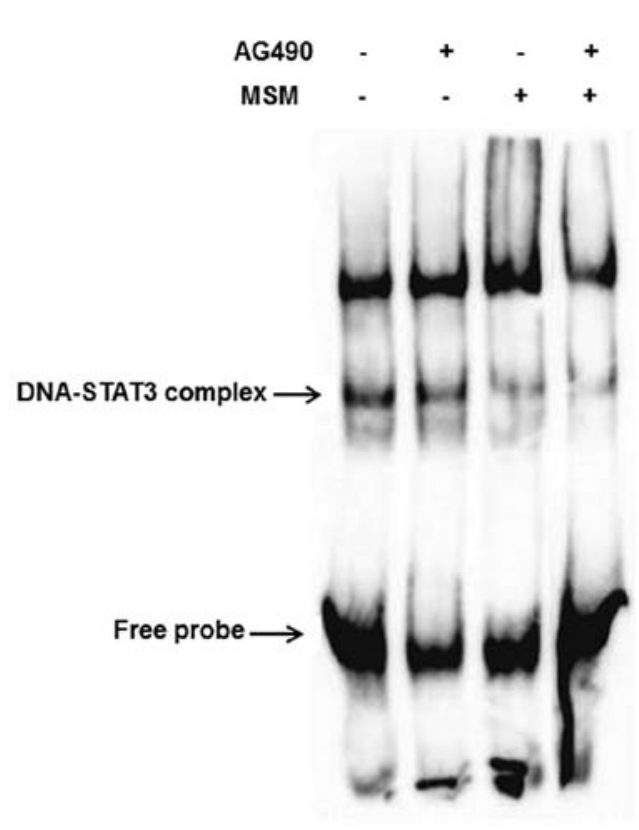

B

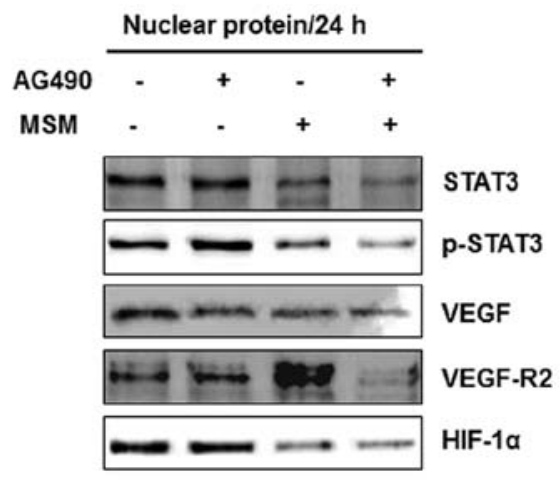

C

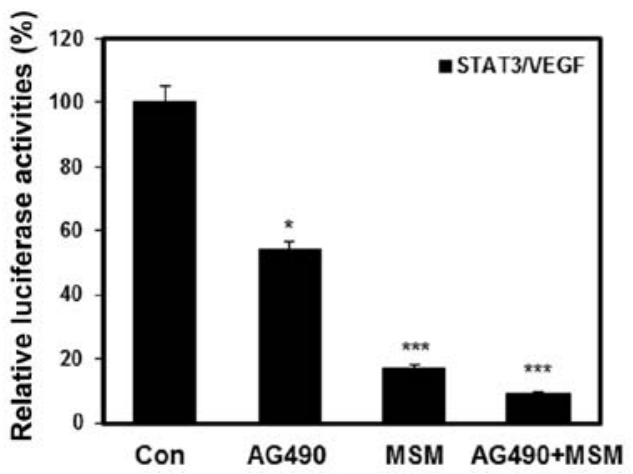

Figure 5. AG490 and MSM combination exposure leads to the downregulation of STAT3 promoter activities. Combination of AG490 and MSM suppressed the binding of STAT3 with VEGF promoter sites. T-24 cells were treated with $25 \mu \mathrm{M}$ AG490 and $300 \mathrm{mM}$ MSM. (A) The effects of individual agents and drug combination on STAT3 DNA binding as detected by EMSA. (B) Protein analysis on nuclear extracts. (C) Inhibition of STAT3/VEGF promoter by AG490 and MSM and combination. COS-7 cells were transiently co-transfected with STAT3 and VEGF and were treated with individual agents and combination. After incubation cells were lysed and lysates were assayed for luciferase activity. Asterisks indicate a statistically significant decreased by ANOVA-test $\left({ }^{*} \mathrm{p}<0.05,{ }^{* * *} \mathrm{p}<0.001\right)$. 
A

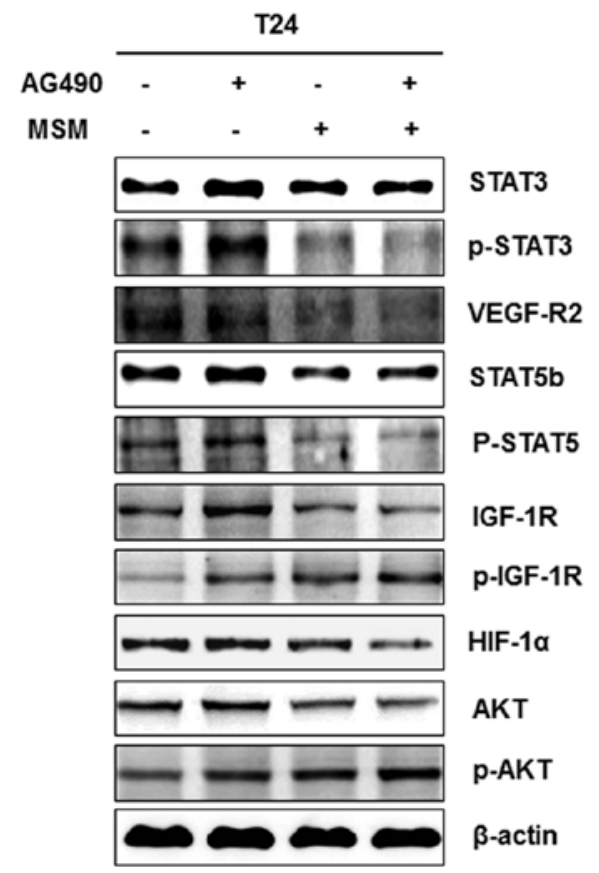

B

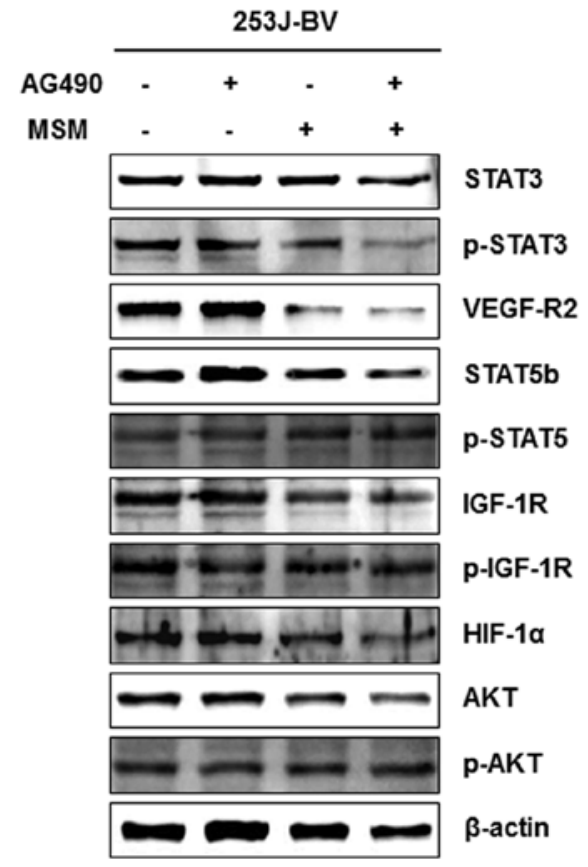

Figure 6. AG490 and MSM combination downregulates the expression of different oncoproteins. The T24 and 253J-BV cells were treated with AG490, MSM and drug combination for $6 \mathrm{~h}$ and the level of protein expression was assayed using western blot analysis. $\beta$-actin was used as a control for protein. (A) Expression of oncoproteins in T24 cells. (B) Expression of proteins in 253J-BV cells.

Exposure of AG490 and MSM combination leads to the downregulation of multiple oncogenic targets in vivo. As shown Fig. 8A, the level of oncogenic protein expression in AG490 and MSM combination treated group decreased markedly compared to MSM treated or control group. The expression levels of STAT3 and its target gene VEGF were analyzed using an immuno-fluorescence microscope. The results showed a decrease in the phosphorylation of STAT3 and thereby decrease in the VEGF expression in AG490 and MSM combination treated group compared to the other two groups (Fig. 8B). Western blot analysis of the xenografts showed a synergistic effect of the drug combination over MSM. The drug combination effectively inhibited the phosphorylation of STAT3 and VEGF (Fig. 8A). Phosphorylation of other oncogenic proteins such as STAT5b and expression of IGF-1R were also suppressed by the drug combination. The major angiogenic factor VEGF and its receptor VEGF-R2 were slighly inhibited by the combination treatment.

Combined treatment with AG490 and MSM induces inhibition of cell migration. Inhibition of cell migration was determined by the in vitro wound healing assay using 253J-BV cells. In wound healing the cells detach from the substratum and move towards the wounded area (9). We made a wound on the confluent culture of 253J-BV cells and monitored the migration of cells into the wound area using live cell microscopy. The control cells showed a higher rate of migration to the wound area. Mild inhibition on migration was observed in plates treated with AG490 and MSM. In the samples treated with drug combination, significant inhibition of migration was detected (Fig. 9).
Oral administration of AG490 and MSM combination inhibits lung metastasis in nude mice. We investigated the possible impact of AG490 and MSM combination in the regression of experimental lung metastasis in vivo. Tumor xenografts were induced in male Balb/c nude mice and were injected with $0.3 \mathrm{mg} / \mathrm{kg}$ MSM or $25 \mu \mathrm{l} / \mathrm{kg}$ AG490 with $0.3 \mathrm{mg} / \mathrm{kg}$ MSM once a day starting two weeks after the inoculation of cells. After 4 weeks, the lungs were collected for histological evaluation. As shown in Fig. 10A, the metastatic cells were distinguishable on $\mathrm{H} \& \mathrm{E}$ stained sections from the lung tissue as densely packed irregularly shaped clusters. Enumeration of the area of metastatic nodes showed four times higher incidence of metastasis in the control group (Fig. 10B).

Combined treatment with AG490 and MSM induces apoptosis. MTT assay on T24 and 253J-BV showed that AG490 and MSM combination had high levels of cytotoxic activity (Fig. 1A). To differentiate this from necrosis and to confirm it as apoptosis, we performed Annexin V-FITC flow cytometry. We quantitated the number of cells undergoing apoptosis. Our results showed that combination of AG490 and MSM induced apoptosis in $43 \%$ of the 253J-BV cells (Fig. 11). The positive control camptothecin $(10 \mu \mathrm{M})$ and actinomycin D $(23 \mu \mathrm{M})$ induced apoptosis approximately 50 and $40 \%$, respectively.

\section{Discussion}

Combination therapy is the approach used in the treatment of many cancers that do not respond to current therapies. This mode of therapy is shown to be safe and effective in 

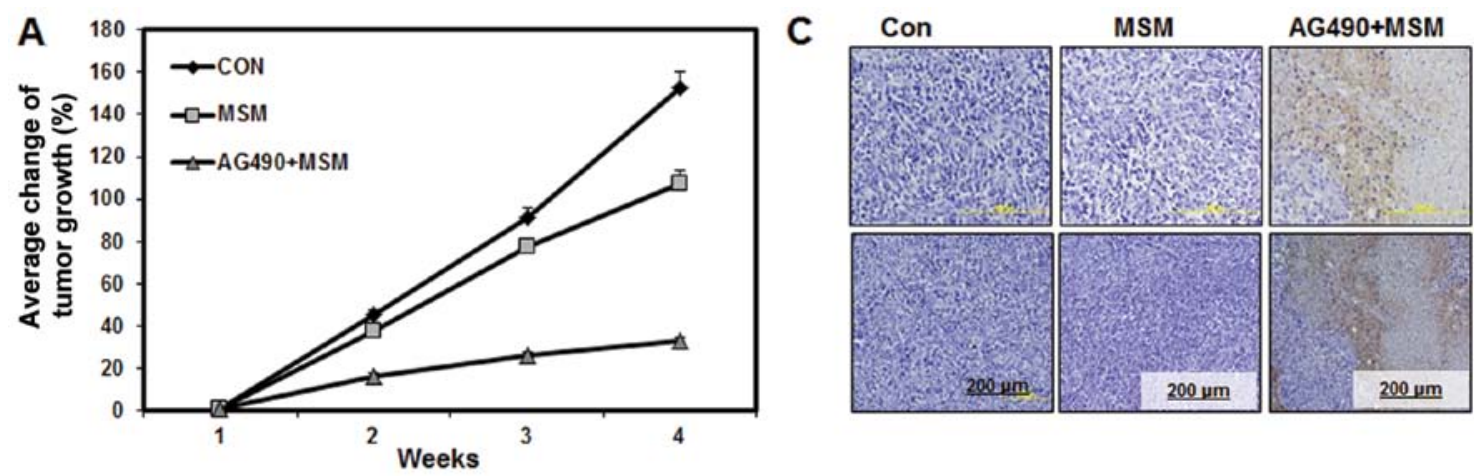

B
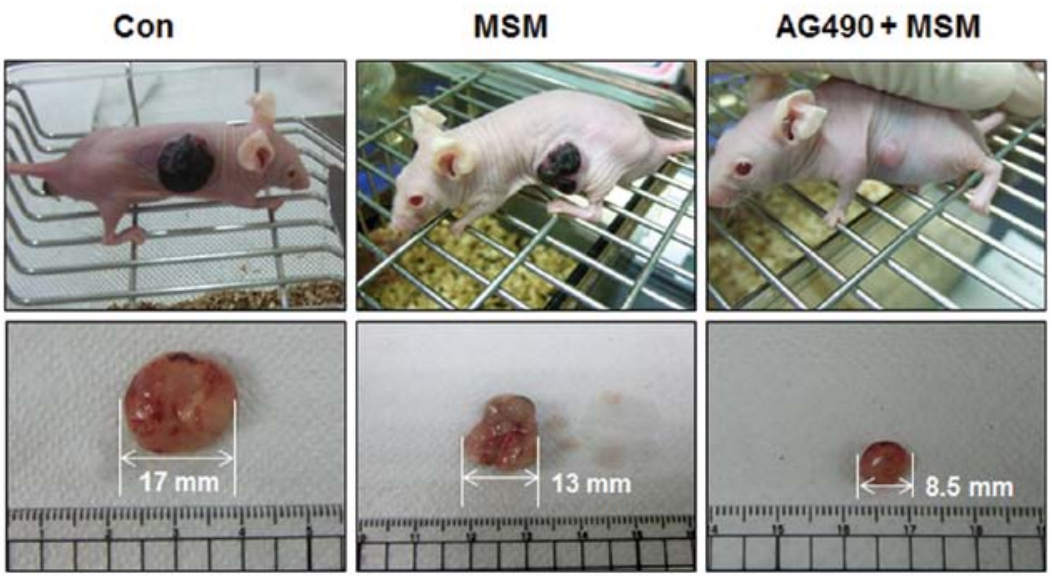

Figure 7. Combination of MSM and AG490 suppressed tumor growth and induced cell death in human bladder cancer xenografted mice. Balb/c male nude mice were subcutaneously injected with 253J-BV cells $\left(1 \times 10^{7}\right)$. Mice were divided into 3 groups and treated with MSM and the drug combination once a day for 4 weeks. No treatment were given to the control group. (A) Change in the tumor volume with treatment time. (B) Image showing the synergistic effect of drug combination on the inhibition of tumor growth. (C) H\&E staining showing the drug combination induced cell death (magnification, $\mathrm{x} 200$ ).

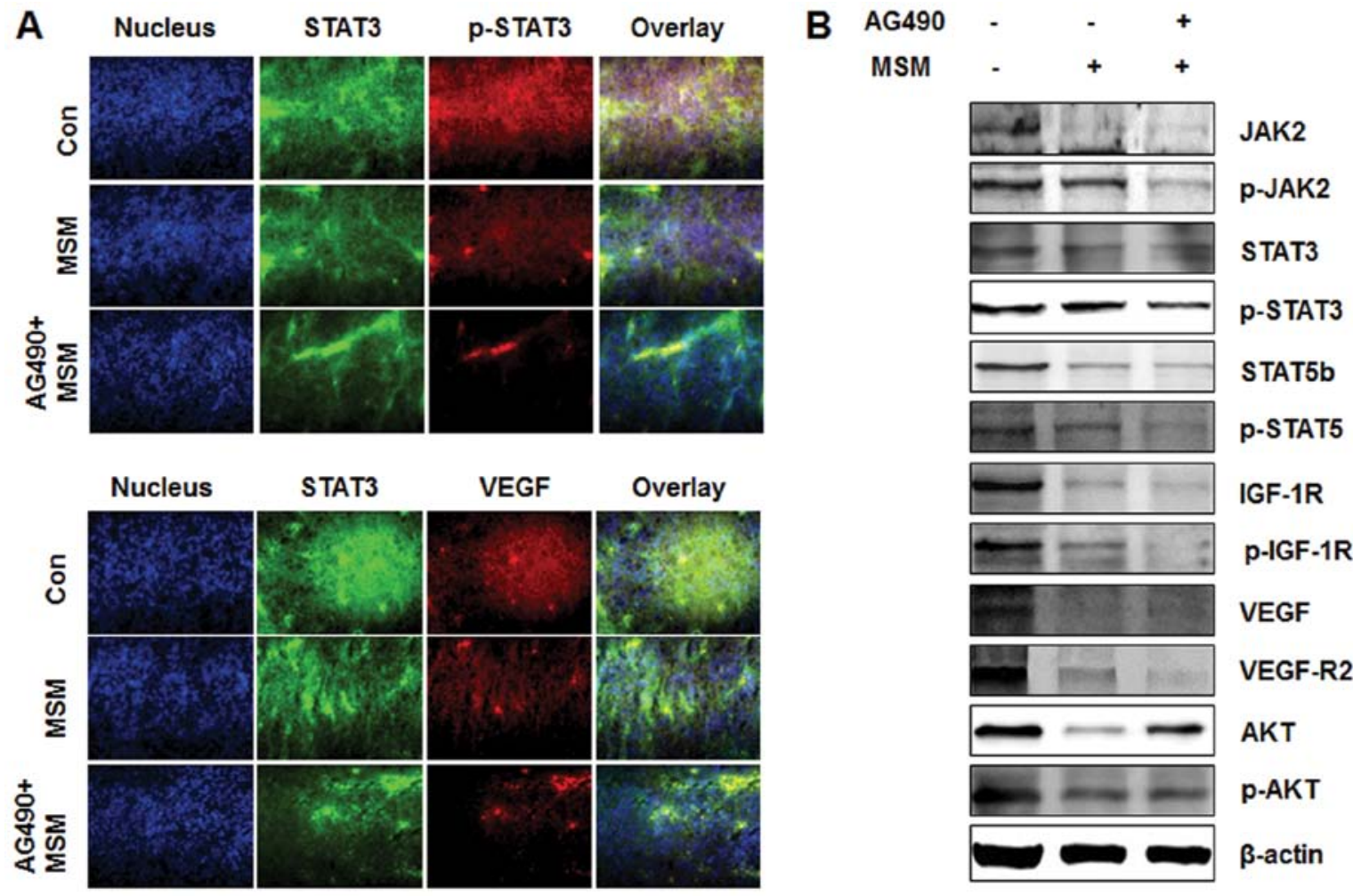

Figure 8. Exposure of AG490 and MSM combination led to the downregulation of multiple oncogenic targets in vivo. The xenografts harvested from the mice were analyzed for the difference in protein expression. (A) Immunohistochemical analysis of xenografts specific for the nucleus, STAT3, p-STAT3 and VEGF showing a decrease in expression. (B) Western blot analysis of xenografts showing downregulation of oncoprotein expression. 
A

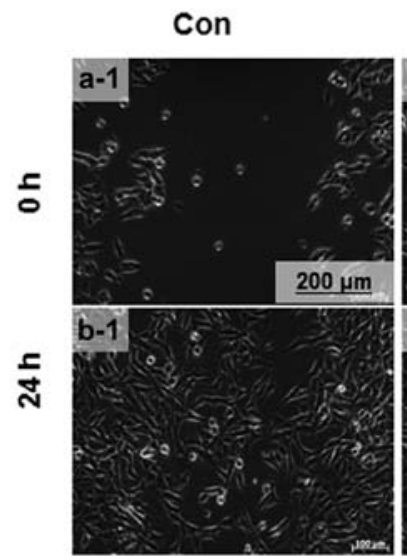

AG490

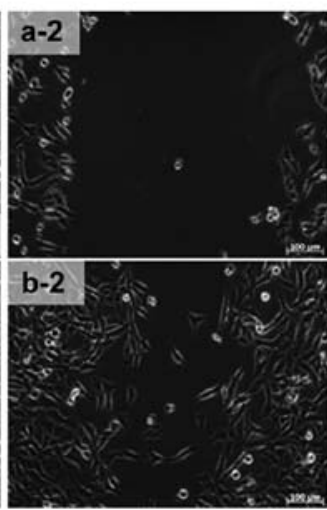

MSM
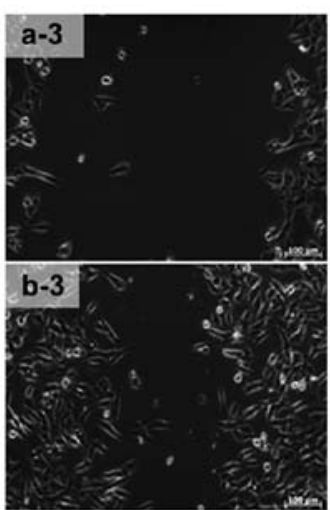

AG490+MSM

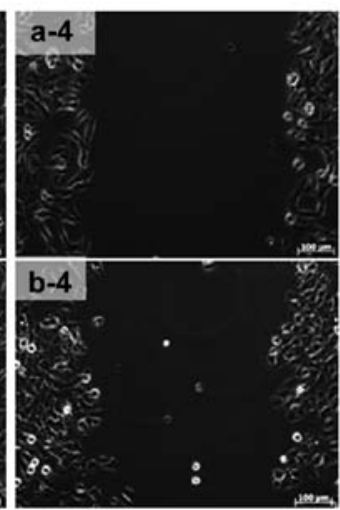

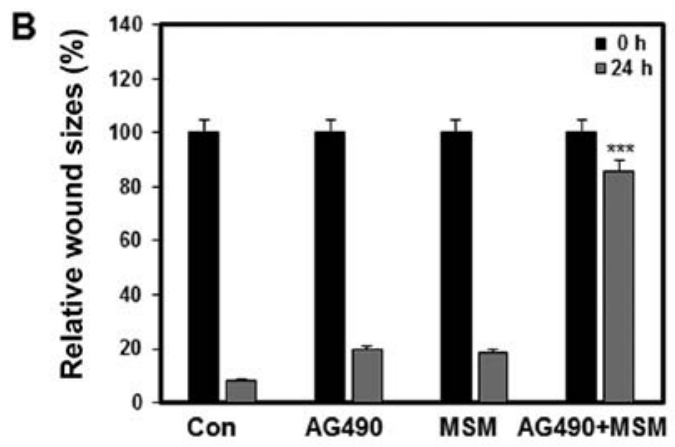

Figure 9. Combined treatment with AG490 and MSM induces inhibition of cell migration. The inhibition of cell migration was studied by wound healing assay. 253J-BV cells were plated on $35-\mathrm{mm}$ tissue culture dish at a concentration of $1 \times 10^{5}$ cells/plate. Once it reached confluence a small wound was made and the cells were treated with AG490, 300 mM MSM and combination of AG490 and MSM. No-treatment was given to the control cells. Wound edges were photographed after 24-h incubation. The plates were videotaped for $24 \mathrm{~h}$. (A) Images showing the wound area before and after incubation. (B) Relative inhibition of migration of cancer cells to the wound area. Asterisks indicate a statistically significant decrease by ANOVA-test $(* * * 00.001)$.

humans. Conventional therapies usually do not have a specific target, instead they work on mass killing of cells. This often results in severe side-effects. Development of target therapies have reduced the side-effects and increased the efficacy in treatment. Combination therapy has made an experimental breakthrough in the targeted therapies. In our present study we used the combination of AG490, a well-known inhibitor of Jak2 and methylsulfonylmethane, a natural organic sulfur containing compound with no known side-effects.

In this study, the efficacy of the drug combination on the inhibition of bladder cancer xenograft growth and its metastasis were analyzed both in vitro and in vivo. In human bladder cancer cell lines T24 and 253J-BV, the drug combination induced cell death at a combination of $25 \mu \mathrm{M}$ AG490 and $300 \mathrm{mM}$ MSM. This concentration of combination was used for further experiments.

Angiogenesis, the formation of new capillaries from existing capillaries is a potential factor of tumor growth and metastasis (34). Pathological angiogenesis is characterized with rapid proliferation of blood vessels and this is involved in various diseases (35). Targeting angiogenesis is the fourth modality of anticancer therapy (36). We demonstrated that combination of AG490 and MSM significantly inhibited angiogenesis and bladder tumor xenograft growth under the valid dosage and treatment time.

Constitutive activation of STAT3 is observed in different types of tumors and promotes cell proliferation and survival
$(37,38)$. STAT3 has become a critical transcription activator biomarker in antigenic therapy of tumor (39). In patients with chemoresistance, STAT3 has been used as the major target for increasing the chemosensitivity (40). STAT3 is upregulated by Jak2. So we aimed to inhibit both Jak2 and STAT3 for anticancer activity. A rapid suppression of Jak2 phosphorylation was observed after the exposure of human bladder cancer cells to drug combination of AG490 and MSM. Inhibition of Jak2 activation inhibited the activation of STAT3. In our study the maximum inhibition on STAT3 activation was achieved at 3-6 h (Fig. 3). Also we found that the drug combination has better capacity to regulate the phosphorylation of STAT3 than the individual agents. It indicates that the drug combination can synergistically inhibit tumor growth more than the individual agents.

Targeting individual molecules for controlling tumor growth is a challenging process and is usually not applicable in different types of cancer. So we tried to inhibit the Jak2/STAT3 pathway, thereby achieving control over all its downstream target genes. The effects of STAT3 inhibition on the downstream genes were analyzed through VEGF expression. VEGF is an important pro-angiogenic factor and induces endothelial cell proliferation and migration (41). Targeting VEGF signal pathway is also a major approach for the development of drugs.

We found a concentration dependent decrease in VEGF expression in bladder cancer cell lines. The regulation was 
A

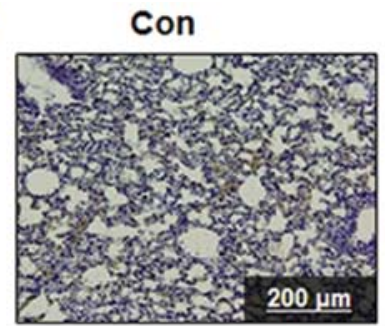

MSM

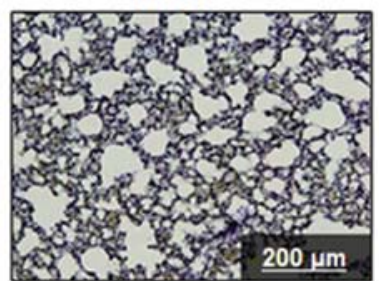

AG490+MSM

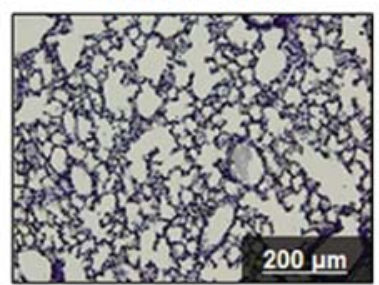

B

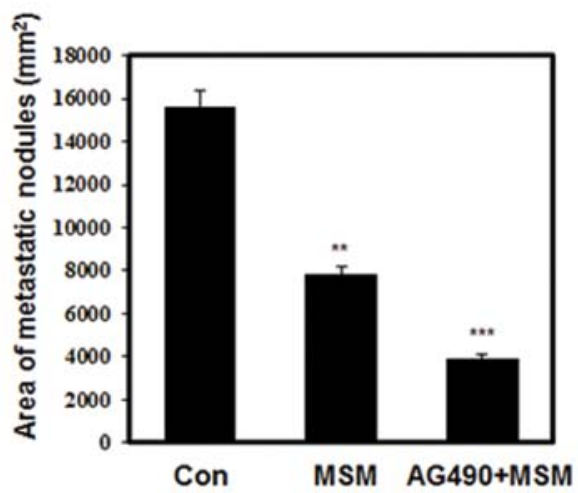

Figure 10. Oral administration of AG490 and MSM combination inhibits lung metastasis in nude mice. Mice were injected with $235 \mathrm{~J}-\mathrm{BV}$ cells $\left(1 \times 10^{7}\right)$ and grouped into three and were treated with MSM and drug combination for the indicated time period. No treatments were given to the control group. After the treatment period lungs were harvested and metastasis were analyzed using H\&E stain. (A) Histological sections showing inhibition of lung metastasis (magnification, x200). (B) Synergistic effect of the drug combination on the inhibition of tumor metastasis. Asterisks indicate a statistically significant decrease in metastasis by ANOVA-test $\left({ }^{* *} \mathrm{p}<0.01,{ }^{* * *} \mathrm{p}<0.001\right)$.

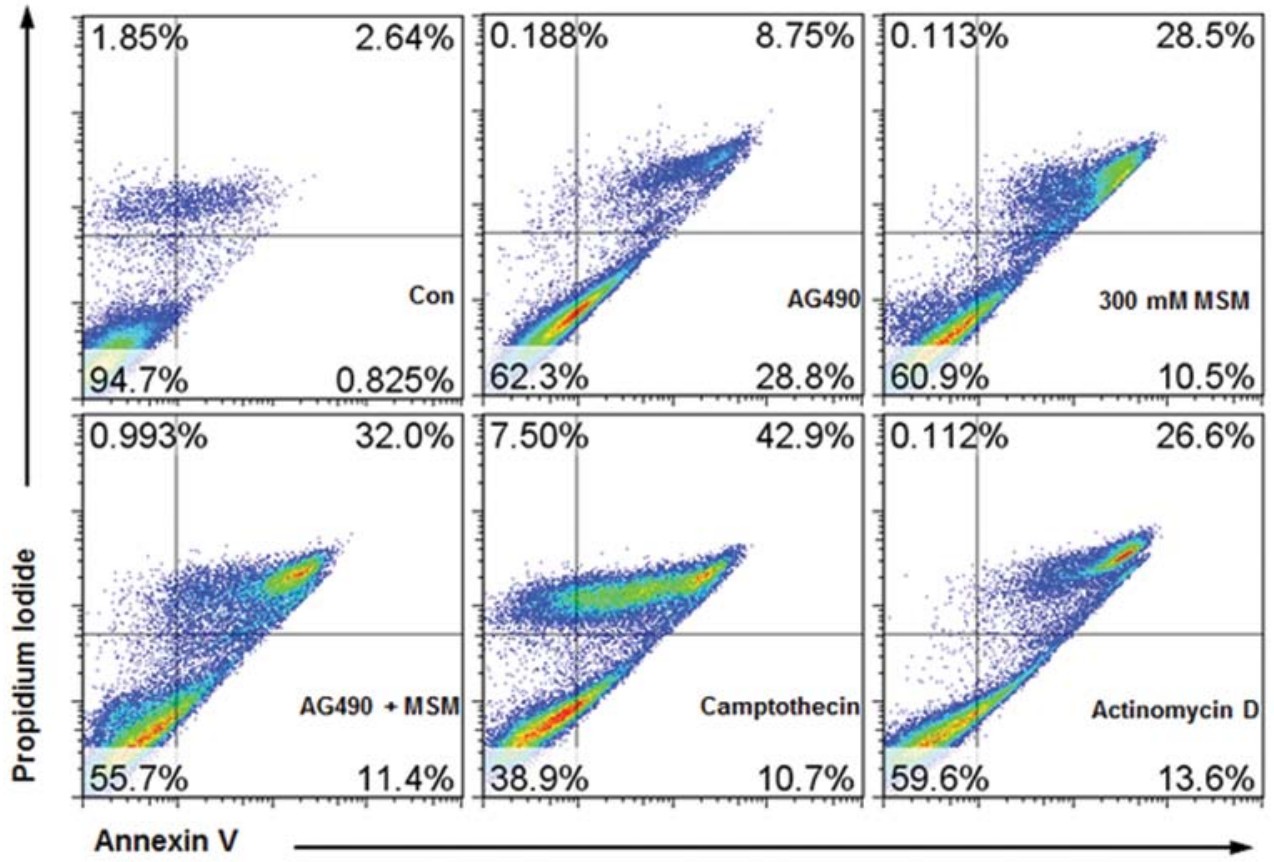

Figure 11. Combined treatment with AG490 and MSM induces apoptosis. 253J-BV cells were treated with AG490, 300 mM MSM, and combination of AG490 and MSM. For positive controls $10 \mu \mathrm{M}$ camptothecin and $23 \mu \mathrm{M}$ actinomycin D were used. Treated cells were analyzed by flow cytometry using Annexin V-FITC as described in Materials and methods, and the percentage of cells in apoptosis was determined. The x-axis represents the fluorescence intensity of Annexin V-FITC, and the y-axis represents the intensity of propidium iodide.

maximal at $6 \mathrm{~h}$ after exposure to the combination treatment. VEGF promoter contains various transcription factor binding sites including STAT3 (42) as well as HIF-1 $\alpha$ (43). Thus, the decrease in transcription factor STAT3 constitutes a decrease in the transcriptional activation of its target genes like VEGF. Maximal inhibition of STAT3 phosphorylation occurred at 
3-6 $\mathrm{h}$; and this in turn resulted in the suppression of VEGF expression. This ability of Jak2/STAT3 pathway in the downregulation of VEGF was confirmed using EMSA and luciferase assay.

The combination treatment showed a higher degree of regulation over different oncoproteins such as STAT5b, IGF-1R and their phosphorylation. VEGF-R2 pathway is the main cascade involved in angiogenesis. Inhibition of VEGF-R2 is the key strategy in anti-angiogenic therapy of cancer (44). The expression of VEGF-R2 is found decreased on exposure to combination treatment irrespective of the cell type.

Cancer becomes lethal once it is metastatic. Cell migration is an important step in the metastatic cascade, similar to invasion and extravasation (45). As Jak2 and STAT3 are the effective modulators for various cellular networks and processes, we analyzed the role of drug combination on cell migration. For eliciting various cellular processes we were in need of higher number of live cells. So we reduced the concentration of MSM in the drug combination to $200 \mathrm{mM}$ which gave $80 \%$ cell viability (Fig. 1). Live cell microscopic observation of the cells exposed to this combination showed, a reduction in cell migration. A similar result was observed in the wound healing assay. Therefore, we believe this combination of drugs has an effective inhibitory role in the metastasis of bladder cancer.

Our in vivo experiments showed that oral administration of combination of MSM and AG490 significantly inhibited the growth of bladder cancer xenografts and lung metastasis. The subcutaneous xenograft model revealed marked reduction in tumor growth rate with the combination of MSM and AG490 in the treated mice compared to controls. The number of metastatic sites give a correlation on survival and response rate of a therapeutic combination (46). Our drug combination induced cell death in vivo, and decreased the incidence of metastasis to the lungs. Lung is a common metastatic site of bladder cancer and other urogenital cancers (47).

The mechanistic aspects of drug combination on the suppression of tumor growth and inhibition of metastasis in the xenografts were studied. IHC studies specific to p-STAT3 and VEGF on xenografts showed a drastic decrease in expression on combination treatment. Western blot analysis showed complete inhibition of Jak2, STAT3 and regulation on the activation of other oncogenic molecules such as STAT5b and downregulated the expression of VEGF, VEGF-R2 and IGF-1R. This confirms the importance of drug combination on the regulation of angiogenesis, cell migration, growth inhibition and induction of apoptosis.

Our findings collectively suggest that therapy with inhibitors of Jak2/STAT3 signaling like AG490 with MSM combination may have a more potent antitumor activity than either treatment alone in human bladder cancer. We have clearly demonstrated the existence of a dose-dependent and cell type-independent inhibitory effect of MSM and AG490 combination on cell proliferation, survival and angiogenesis in human urinary bladder cancer cells. In addition, the data showed the oral efficacy of drug combination on the suppression of bladder cancer growth and metastasis. The inhibition of the activated Jak2/STAT3 pathway, at least in part, contributed to the anti-proliferative, anti-angiogenic effects, and apoptosis. Therefore, this combination could be a novel basis for small molecules targeting angiogenesis and of therapeutic significance in the treatment of angiogenesisrelated diseases.

\section{Acknowledgements}

This study was supported by the Konkuk University, Seoul, Republic of Korea.

\section{References}

1. Wu XR: Urothelial tumorigenesis: a tale of divergent pathways. Nat Rev Cancer 5: 713-725, 2005.

2. Baselli EC and Greenberg RE: Intravesical therapy for superficial bladder cancer. Oncology 14: 719-729, 2000.

3. Malmström P: Improved patient outcomes with BCG immunotherapy vs. chemotherapy - Swedish and worldwide experience. Eur Urol 37 (Suppl 1): S16-S20, 2000.

4. Sekine H, Ohya K, Kojima SI, Igarashi K and Fukui I: Equivalent efficacy of mitomycin C plus doxorubicin instillation to bacillus Calmette-Guerin therapy for carcinoma in situ of the bladder. Int J Urol 8: 483-486, 2001.

5. Jemal A, Bray F, Center MM, Ferlay J, Ward E and Forman D: Global cancer statistics. CA Cancer J Clin 61: 69-90, 2001.

6. Lee JI, Min HK, Lee JW, Jeong JD, Ha YJ, Kwack SC and Park JS: Change in the quality of loin from pigs supplemented with dietary methyl sulfonyl methane during cold storage. Korean J Food Sci Ani Resour 29: 299-237, 2009.

7. Joung YH, Lim EJ, Darvin P, Chung SC, Jang JW, Park KD, Lee HK, Kim HS, Park TK and Yang YM: MSM enhances GH signaling via the Jak2/STAT5b pathway in osteoblast-like cells and osteoblast differentiation through the activation of STAT5b in MSCs. PLoS One 7: e47477, 2012.

8. Lim EJ, Hong DY, Park JH, Joung YH, Pramod D, Pak SH, Na YM, Hwang TS, Ye SK, Moon ES, Cho BW, Park KD, Lee HK and Yang YM: Methylsulfonylmethane down-regulates the STAT3/VEGF pathway in MDA-MB 231 cells and suppresses tumor growth of breast cancer xenografts. PLoS One 7: e33361, 2011.

9. Caron JM, Bannon M, Rosshirt L, Luis J, Montaegudo L, Caron JM and Sternstein GM: Methyl sulfone induces loss of metastatic properties and reemergence of normal phenotype in a metastatic cloudman S-91 (M3) murine melanoma cell line. PLoS One 5: e11788, 2010.

10. Caron JM, Bannon M, Rosshirt L and O'Donovan L: Methyl sulfone manifests anticancer activity in a metastatic murine breast cancer cell line and in human breast cancer tissue part I: murine 4T1 (66 cl-4) cell line. Chemotherapy 59: 14-23, 2013.

11. Caron JM, Monteagudo L, Sanders M, Bannon $M$ and Deckers PJ: Methyl sulfone manifests anticancer activity in a metastatic murine breast cancer cell line and in human breast cancer tissue - part 2: human breast cancer tissue. Chemotherapy 59: 24-34, 2013.

12. Ihle JN: STATs: signal tranducers and activators of transcription. Cell 84: 331-334, 1996.

13. Seo IA, Lee HK, Shin YK, Lee SH, Seo SY, Park JW and Park HT: Janus kinase 2 inhibitor AG490 inhibits the STAT3 signaling pathway by suppressing protein translation of gp130. Korean J Physiol Pharmacol 13: 131-138, 2009.

14. Samanta AK, Lin H, Sun T, Kantarjian H and Arlinghaus RB: Janus kinase 2: a critical target in chronic myelogenous leukemia. Cancer Res 66: 6468-6472, 2006.

15. Miyamoto N, Sugita K, Goi K, Inukai T, Lijima K, Tezuka T, Kojika S, Nakamura M, Kagami K and Nakazawa S: The JAK2 inhibitor AG490 predominantly abrogates the growth of human B-precursor leukemic cells with 11q23 translocation or Philadelphia chromosome. Leukemia 15: 1758-1768, 2001.

16. Meydan N, Grunberger T, Dadi H, Shahar M, Arpaia E, Lapidot Z, Leeder JS, Freedman M, Cohen A, Gazit A, Levitzki A and Roifman CM: Inhibition of acute lymphoblastic leukaemia by a Jak-2 inhibitor. Nature 379: 645-648, 1996.

17. Ferrajoli A, Faderl S, Van Q, Koch P, Harris D, Liu Z, Hazan-Halevy I, Wang Y, Kantarjian HM, Priebe W and Estrov Z: WP1066 disrupts Janus kinase-2 and induces caspase-dependent apoptosis in acute myelogenous leukemia cells. Cancer Res 67: 11291-11299, 2007. 
18. Verstovsek S, Manshouri T, Quintás-Cardama A, Harris D, Cortes J, Giles FJ, Kantarjian H, Priebe W and Estrov Z: WP1066, a novel JAK2 inhibitor, suppresses proliferation and induces apoptosis in erythroid human cells carrying the JAK2 V617F mutation. Clin Cancer Res 14: 788-796, 2008.

19. Turkson J and Jove R: STAT proteins: novel molecular targets for cancer drug discovery. Oncogene 19: 6613-6626, 2000.

20. Darnell JE Jr: STATs and gene regulation. Science 277 $1630-1635,1997$.

21. Bromberg JF: Activation of STAT proteins and growth control Bioessays 23: 161-169, 2001.

22. Fernandes A, Hamburger AW and Gerwin BI: ErbB-2 kinase is required for constitutive stat 3 activation in malignant human lung epithelial cells. Int J Cancer 83: 564-570, 1999.

23. Buettner R, Mora LB and Jove R: Activated STAT signaling in human tumors provides novel molecular targets for therapeutic intervention. Clin Cancer Res 8: 945-954, 2002.

24. Ren Z and Schaefer TS: ErbB-2 activates Stat $3 \alpha$ in a Srcand JAK2-dependent manner. J Biol Chem 277: 38486-38493, 2002 .

25. Halachmi S, Aitken KJ, Szybowska M, Sabha N, Dessouki S, Lorenzo A, Tse D and Bagli DJ: Role of signal transducer and activator of transcription 3 (STAT3) in stretch injury to bladder smooth muscle cells. Cell Tissue Res 326: 149-158, 2006.

26. Opdam FJ, Kamp M, de Bruijn R and Roos E: Jak kinase activity is required for lymphoma invasion and metastasis. Oncogene 23: 6647-6653, 2004

27. Mijatovic T, Mathieu V, Gaussin JF, De Neve N, Ribaucour F, Van Quaquebeke E, Dumont P, Darro F and Kiss R: Cardenolide-induced lysosomal membrane permeabilization demonstrates therapeutic benefits in experimental human non-small cell lung cancers. Neoplasia 8: 402-412, 2006.

28. Wu W, Shu X, Hovsepyan H, Mosteller RD and Broek D: VEGF receptor expression and signaling in human bladder tumors. Oncogene 22: 3361-3370, 2003.

29. Laramée M, Chabot C, Cloutier M, Stenne R, HolgadoMadruga M, Wong AJ and Royal I: The scaffolding adapter Gab1 mediates vascular endothelial growth factor signaling and is required for endothelial cell migration and capillary formation. J Biol Chem 282: 7758-7769, 2007.

30. Semenza, GL, Jiang BH, Leung SW, Passantino R, Concordet JP, Maire $\mathrm{P}$ and Giallongo A: Hypoxia response elements in the aldolase A, enolase 1 and lactate dehydrogenase A gene promoters contain essential binding sites for hypoxia-inducible factor 1. J Biol Chem 271: 32529-32537, 1996

31. Jung JE, Lee HG, Cho IH, Chung DH, Yoon SH, Yang YM, Lee JW, Choi S, Park JW and Ye SK: STAT3 is a potential modulator of HIF-1-mediated VEGF expression in human renal carcinoma cells. FASEB J 19: 1296-1298, 2005.

32. Joung YH, Lim EJ, Lee MY, Park JH, Ye SK, Park EU, Kim SY, Zhang Z, Lee KJ, Park DK, Park T, Moon WK and Yang YM: Hypoxia activates the cyclin D1 promoter via the Jak2/STAT5b pathway in breast cancer cells. Exp Mol Med 37: 353-364, 2007.
33. Joung YH, Park JH, Park TK, Lee CS, Kim OH, Ye SK, Yang UM, Lee KJ and Yang YM: Hypoxia activates signal transducers and activators of transcription 5 (STAT5) and increases its binding activity to the GAS element in mammary epithelial cells. Exp Mol Med 35: 350-357, 2003.

34. Ellis L, Hammers H and Pili R: Targeting tumor angiogenesis with histone deacetylase inhibitors. Cancer Lett 280: 145-153, 2009.

35. Folkman J: Angiogenesis: an organizing principle for drug discovery? Nat Rev Drug Discov 6: 273-286, 2007.

36. Folkman J: Endogenous angiogenesis inhibitors. APMIS 112: 496-507, 2004.

37. Hodge DR, Hurt EM and Farrar WL: The role of IL-6 and STAT3 in inflammation and cancer. Eur J Cancer 41: 2502-2512, 2005.

38. Haura EB, Turkson $\mathrm{J}$ and Jove R: Mechanisms of disease: Insights into the emerging role of signal transducers and activators of transcription in cancer. Nat Clin Pract Oncol 2: 315-324, 2005.

39. Chen SH, Murphy DA, Lassoued W, Thurston G, Feldman MD and Lee WM: Activated STAT3 is a mediator and biomarker of VEGF endothelial activation. Cancer Biol 7: 1994-2003, 2008.

40. Chen RJ, Ho YS, Guo HR and Wang YJ: Long term nicotine exposure-induced chemoresistance is mediated by activation of Stat3 and downregulation of ERK12 via nAChR and beta-adrenoceptors in human bladder cancer cells. Toxicol Sci 115: 118-130, 2010.

41. McColl BK, Stacker SA and Achen MG: Molecular regulation of the VEGF family-inducers of angiogenesis and lymphangiogenesis. APMIS 112: 463-480, 2004.

42. Niu G, Wright KL, Huang M, Song L, Haura E, Turkson J, Zhang S, Wang T, Sinibaldi D, Coppola D, Heller R, Ellis LM, Karras J, Bromberg J, Pardoll D, Jove R and Yu H: Constitutive Stat3 activity up-regulates VEGF expression and tumor angiogenesis. Oncogene 21: 2000-2008, 2002.

43. Forsythe JA, Jiang BH, Iyer NV, Agani F, Leung SW, Koos RD and Semenza GL: Activation of vascular endothelial growth factor gene transcription by hypoxia-inducible factor 1 . Mol Cell Biol 16: 4604-4613, 1996.

44. Dong Y, Lu B, Zhang X, Zhang J, Lai L, Li D, Wu Y, Song Y, Luo J, Pang X, Yi Z and Liu M: Cucurbitacin E, a tetracyclic triterpenes compound from Chinese medicine, inhibits tumor angiogenesis through VEGFR2-mediated Jak2-STAT3 signaling pathway. Carcinogenesis 31: 2097-2104, 2010.

45. Guo W and Giancotti FG: Integrin signalling during tumour progression. Nat Rev Mol Cell Biol 5: 816-826, 2004.

46. Parimoo D and Raghavan D: Progress in the management of metastatic bladder cancer. Cancer Control 7: 347-356, 2000.

47. Raghavan D, Shipley WU, Garnick MB, Russell PJ and Richie JP: Biology and management of bladder cancer. N Engl J Med 322: 1129-1138, 1990 